\title{
Secondary Causes of Myositis
}

\author{
Sarah H. Berth, MD, PhD \\ Thomas E. Lloyd, MD, PhD*
}

\author{
Address \\ *Department of Neurology, School of Medicine, Johns Hopkins University, Balti- \\ more, MD, USA \\ Email: tlloyd4@jhmi.edu
}

Published online: 6 October 2020

(C) Springer Science+Business Media, LLC, part of Springer Nature 2020

This article is part of the Topical Collection on Neurologic Manifestations of Systemic Disease

Keywords Inflammatory myopathy · SARS-CoV-2 - HIV myositis - Immune checkpoint inhibitors · Anti-HMGCR . Malignancy-associated myositis · Overlap myositis · Immunosuppression

\begin{abstract}
Purpose of review The purpose of this paper is to comprehensively evaluate secondary causes of inflammatory myopathies (myositis) and to review treatment options. Recent findings This review highlights recent advancements in our understanding of known causes of myositis, including newer drugs that may cause myositis such as checkpoint inhibitors and viruses such as influenza, HIV, and SARS-CoV2. We also discuss treatment for malignancy-associated myositis and overlap myositis, thought to be a separate entity from other rheumatologic diseases.

Summary Infections, drugs, rheumatologic diseases, and malignancies are important causes of myositis and are important to diagnose as they may have specific therapies beyond immunomodulatory therapy.
\end{abstract}

\section{Introduction}

The term "myositis" is often used interchangeably with "idiopathic inflammatory myopathy" (IIM), referring to primary autoimmune diseases of muscle including dermatomyositis, inclusion body myositis (IBM), antisynthetase syndrome, and necrotizing autoimmune myopathy [1-6]. However, there are also known causes of inflammatory myopathies which must be considered in the evaluation of patients with acute or subacute myopathy, including infections, drugs, mixed connective tissue disease, and malignancies. Furthermore, while polymyositis is classically included in IIMs, most cases are now thought to either be early IBM or secondary to another disease such as those covered here. As several excellent recent reviews have covered treatment of IIM $[6,7 \bullet \bullet, 8]$, this review will focus on known, or secondary, causes of myositis.

Infectious myositis can occur with bacterial, viral, fungal, or parasitic infections. Bacterial myositis, which is typically focal, can occur via hematogenous spread (pyomyositis) or via spread from contiguous infection or trauma [9]. While a range of bacteria can cause pyomyositis, the most common is Staphylococcus aureus, which causes up to $90 \%$ of cases in tropical regions and up to $70 \%$ in the USA [10,11]. The most common cause of bacterial myositis not due to 
hematogenous spread is Streptococcus, whereas myositis in the setting of trauma is typically due to polymicrobial infection [9]. Viral myositis is most commonly caused by influenza and enterovirus but can be caused by many different classes of viruses [12], and clinical presentations range from myalgias to focal myositis to rhabdomyolysis. Myalgias are typically an initial presenting symptom of influenza, whereas myositis usually follows days of illness and is marked by pain and swelling. In progression to rhabdomyolysis, muscle pain and weakness typically become diffuse and are accompanied by a marked increase in serum creatine kinase (CK) enzyme level and myoglobinuria. A recent retrospective case study from Wuhan on neurologic complications of SARSCoV-2 indicates that infectious myositis may also be a complication of SARS-CoV-2, as close to $10 \%$ of patients had muscle injury as defined by the presence of myalgias and CK $>200$ units per liter (U/L) $[13 \bullet]$. Typically, viral myositis is treated symptomatically and resolves within days. An exception to this is HIV-associated myositis which presents with both proximal and distal weakness progressing over weeks to months that clinically and pathologically overlaps with inclusion body myositis (IBM) [14•]. Finally, fungal and parasitic infections have been reported to cause myositis. Fungal myositis is rare and usually occurs in immunocompromised hosts, whereas parasitic myositis occurs in endemic regions; the most common causes include Trichinella, Taenia solium, and Toxoplasma gondii [9].

Medications have also been linked to myositis. Statins commonly cause myalgias, but are also rarely associated with an autoimmune necrotizing myopathy and autoantibodies to 3-hydroxy-3 methylglutaryl-coenzyme A reductase (HMGCR) [15]. Most (63\%) patients with anti-HMGCR myositis were previously exposed to statins [16], though anti-HMGCR myositis can also present in statin- naïve patients. Immune checkpoint inhibitors (ICI) are a class of drugs recently developed for cancer treatment, for which myositis has been recognized as an immune-related adverse event. Myositis in these patients can occur along with other autoimmune syndromes, most commonly myasthenia gravis or myocarditis [17]. Myositis typically occurs early in the course of treatment, with one study showing median onset 25 days after initiation of ICI [18]. Other medications that have been linked to myositis include penicillamine [19, 20], interferon beta [21], and TNF $\alpha$ inhibitors [22]. In this era of COVID-19, it is important to note that chloroquine and hydroxychloroquine, used to treat or prevent SARS-CoV-2, can cause a progressive myopathy characterized by autophagic vesicles [23•].

Myositis has also been associated with connective tissue diseases, including systemic sclerosis, systemic lupus erythematosus (SLE), mixed connective tissue disease, and Sjögren's syndrome. Recent studies suggest that myositis in patients with systemic sclerosis confers a worse prognosis than those without myositis $[24,25]$, suggesting that overlap myositis should guide treatment decisions in these patients.

Finally, myositis can also be secondary to underlying malignancy. Autoimmune necrotizing myopathy, dermatomyositis, and polymyositis have all been associated with malignancies [26, 27]. Risk of malignancy is highest in the year prior to and following diagnosis [28-34], and it is associated with older age [33, 35,36], male sex [37], cutaneous necrosis [37, 38], rapid onset of disease [38], high inflammatory markers $[38,39]$, and resistance to treatment [29]. In dermatomyositis, the presence of NXP-2 and TIF-1 $\gamma$ antibodies are also associated with an increased risk of malignancy [40]. Of note, myositis can be a rare feature of chronic graft versus host disease (cGVHD), a complication of allogeneic stem cell transplantations [41-43].

\section{Treatment of secondary myositis}

For an overview of commonly used medications to treat myositis, see Table 1 . While these are the most common medications used to treat both primary (IIM) and secondary causes, this is not a comprehensive list, and the use of these and other medications is discussed in detail elsewhere [68]. 


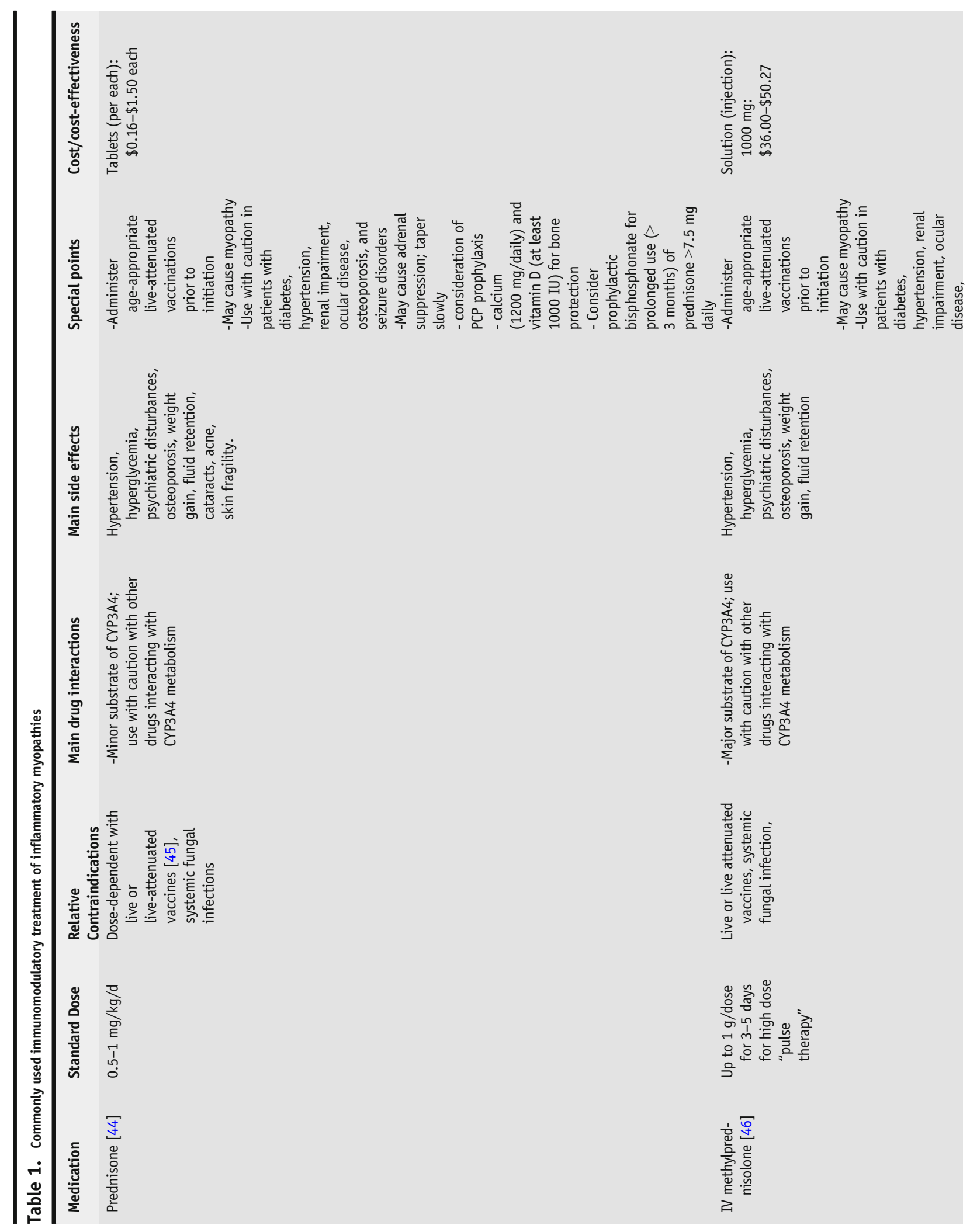




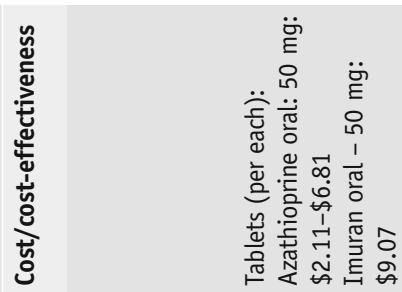

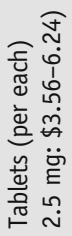

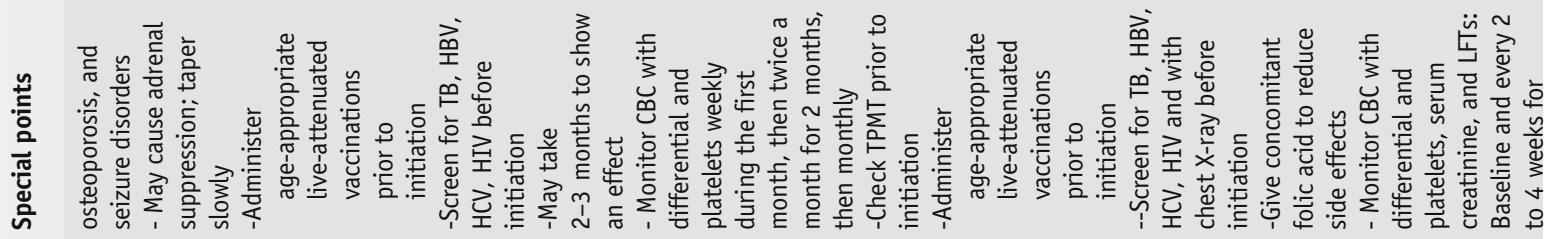
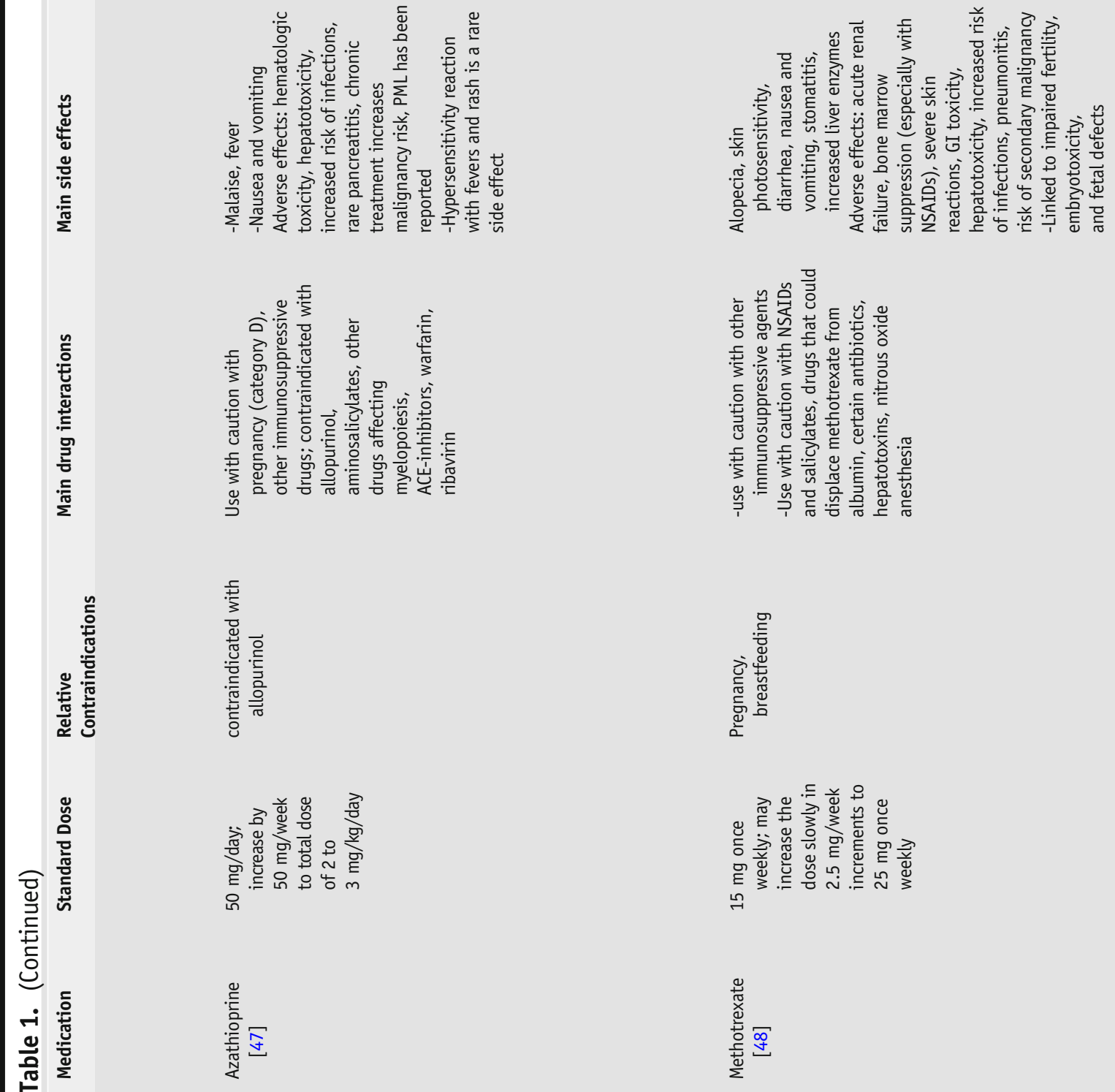


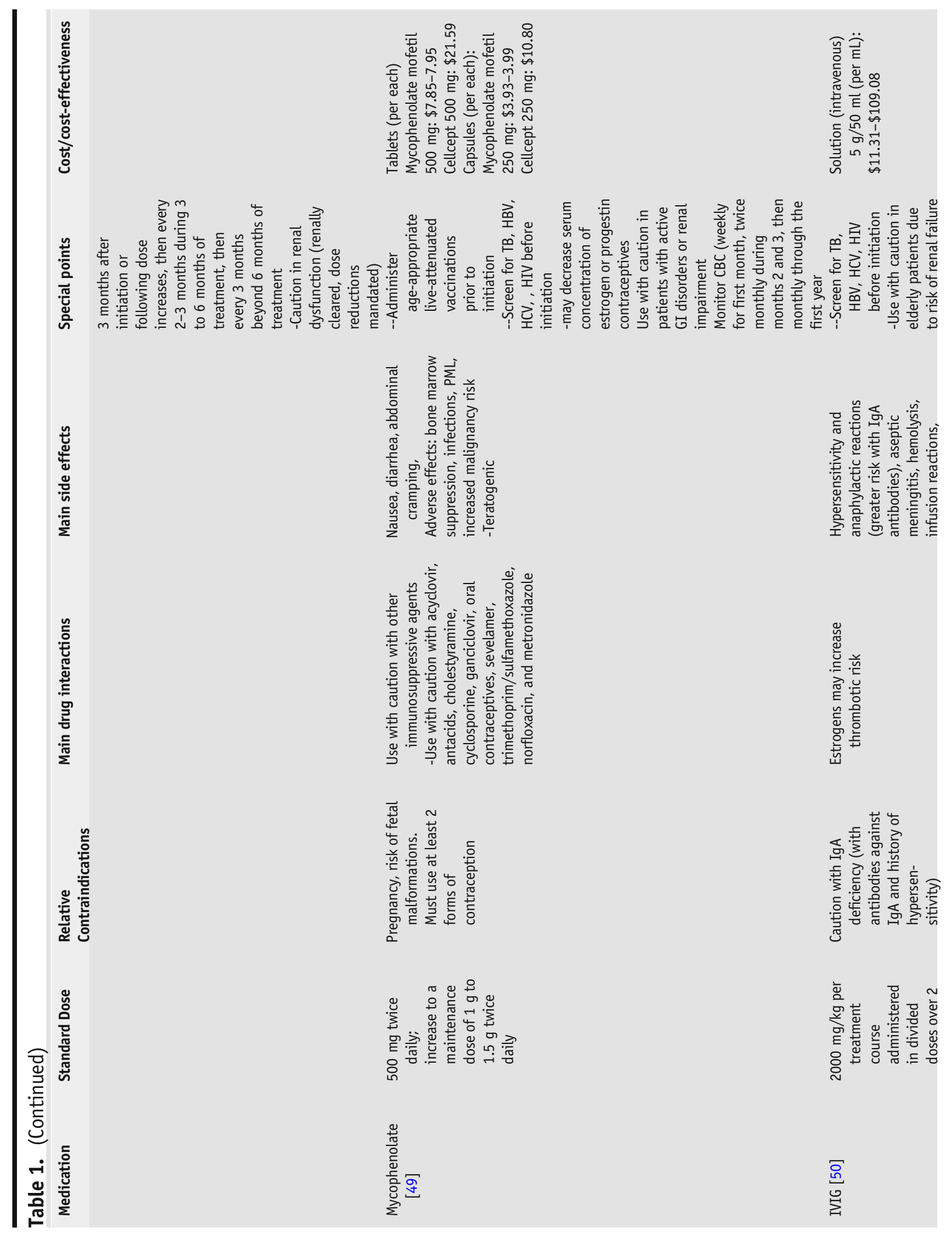



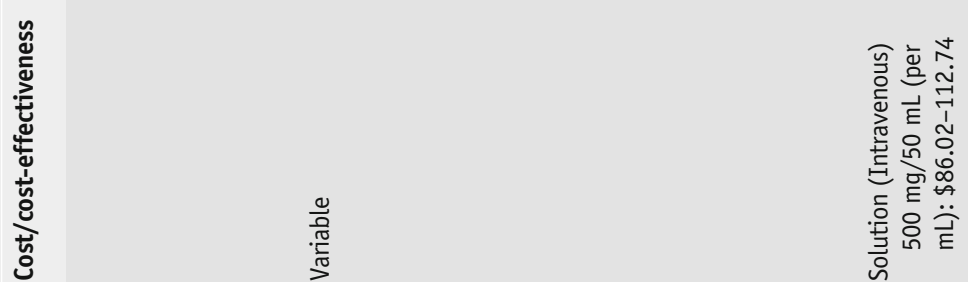

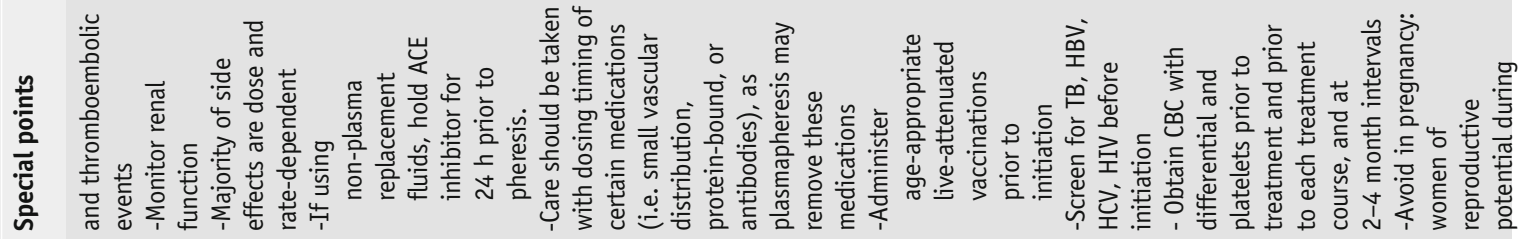
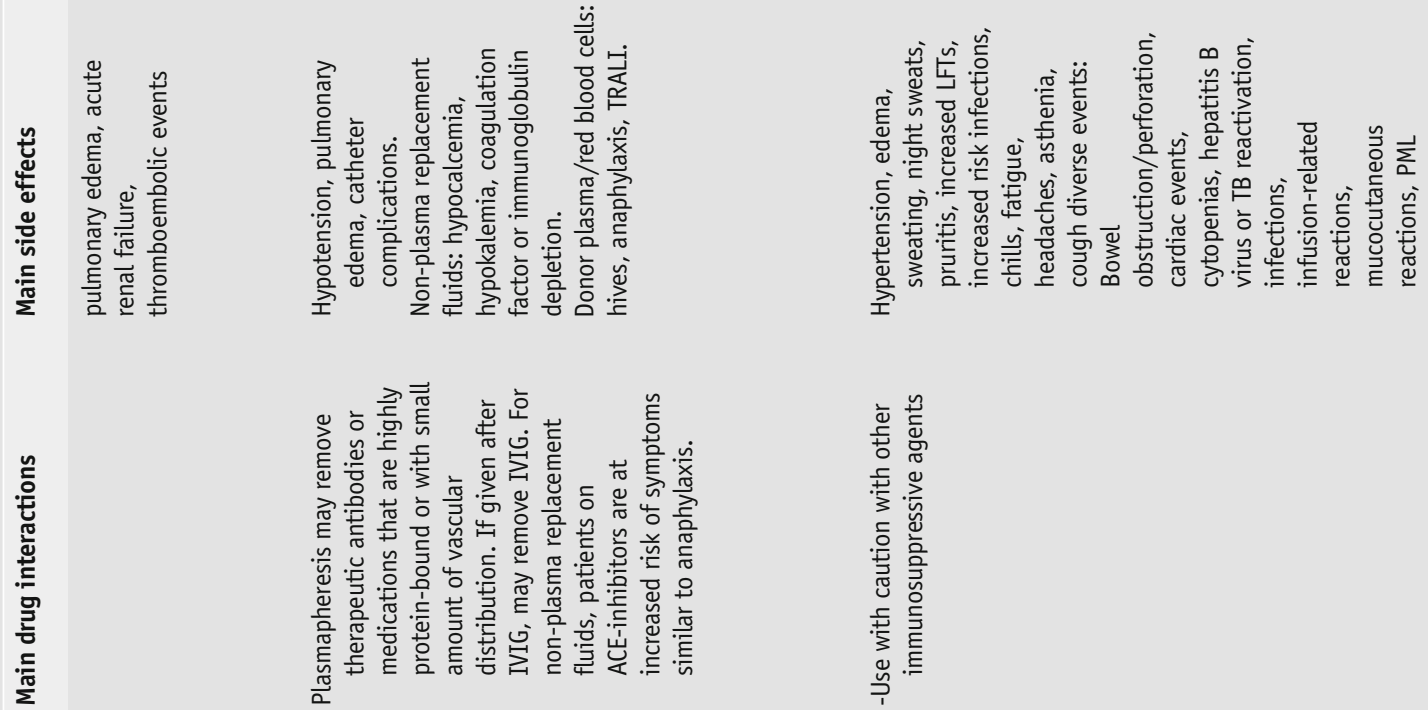

吾高
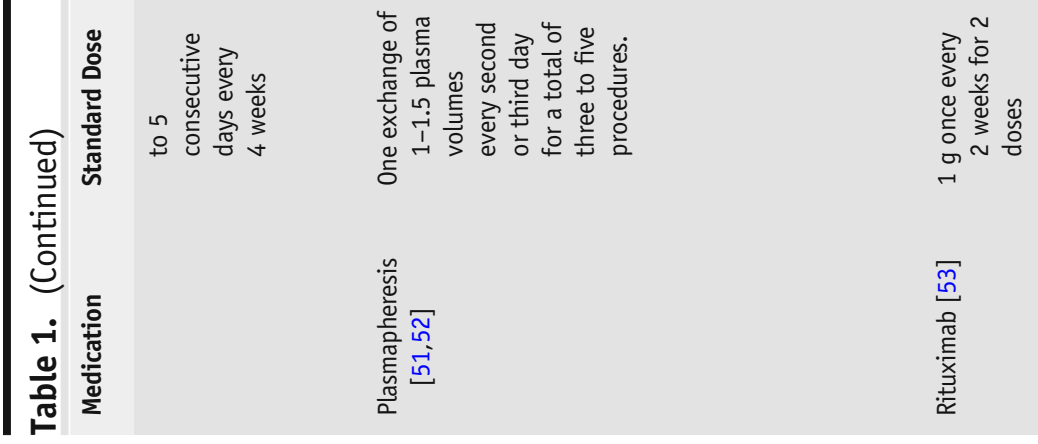

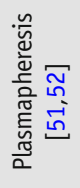

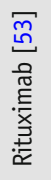




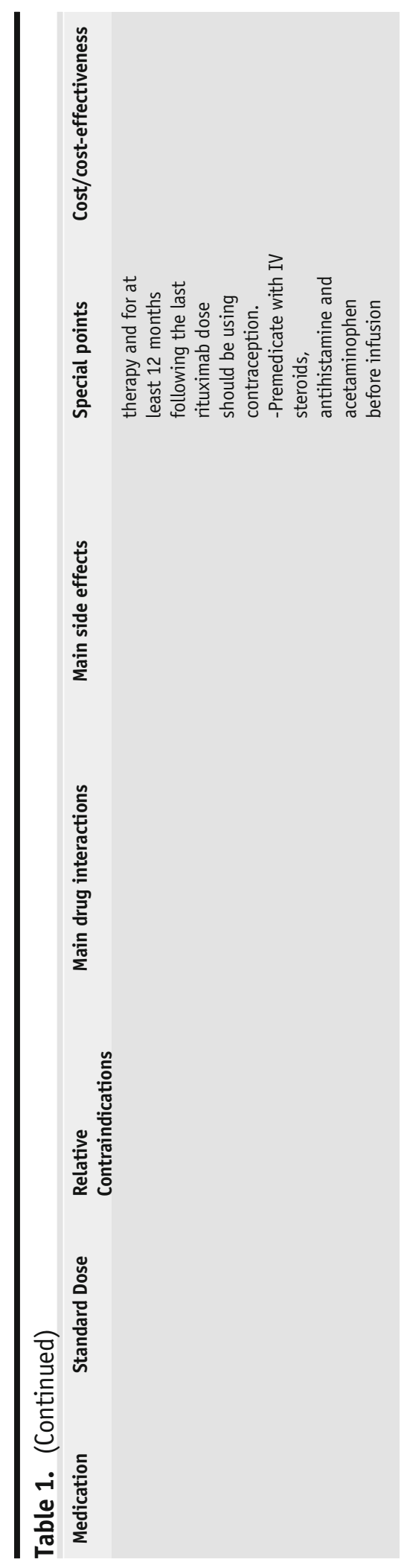


For viral infectious myositis, patients are treated with hydration, rest, and analgesics, and symptoms usually resolve within days [12]. For HIVassociated myositis, one study of 11 patients showed patients treated with immunosuppressive medications had improvement in proximal weakness despite the progression of distal weakness, though it is unclear if this improvement may be due to the natural progression of disease [14•]. In this case series, several patients improved with initial treatment of prednisone transitioned to steroid-sparing agents such as mycophenolate or azathioprine. In our opinion, it is reasonable to initiate a trial of immunosuppressive therapy in HIVassociated myositis with consultation of an infectious disease physician. Treatment of bacterial, fungal, or parasitic myositis will require antibacterial, antifungal, or antihelminthic therapy, respectively [9].

\section{Medication-induced myositis}

\section{HMGCR antibodies associated with statin use}

For patients with anti-HMGCR antibodies, cessation of statin therapy is important [54]. For patients that require cholesterol-lowering medication, proprotein convertase subtilisin/kexin type 9 (PCSK9) can be considered, as these medications were shown to be safe in a case series of 8 patients with HMGCR antibodypositive necrotizing myopathies [55]. In rare mild cases, further treatment beyond statin cessation may not be necessary [54]. For immune treatment, expert consensus recommends initial treatment with steroids (oral steroids at $1 \mathrm{mg} / \mathrm{kg} /$ day or IV steroids $0.5-1 \mathrm{~g} /$ day for 3-5 days) with initiation of azathioprine, methotrexate, mycophenolate, or intravenous immunoglobulin (IVIG) [2]. IVIG monotherapy may be considered in patients with comorbidities that could be worsened with steroids, such as diabetes mellitus or osteoporosis [56]. In refractory or relapsing patients, rituximab may be considered $[2,57,58]$.

\section{ICI-associated myositis}

Expert guidelines recommend the treatment of ICI-associated myositis tailored to severity [59••]. For mild weakness without CK elevation, patients may be offered analgesia, and ICI may be continued with careful monitoring of CK. For mild or moderate weakness with CK elevation, it is recommended for ICIs to be held, and prednisone can be initiated at $0.5-1 \mathrm{mg} / \mathrm{kg}$. These cases may require permanent discontinuation. For severe weakness limiting activities of daily living, cessation of ICI and referral to a neurologist or rheumatologist with expertise in managing myositis are recommended. In this case, patients can be treated with $1-2 \mathrm{mg} / \mathrm{kg}$ prednisone (use higher dose if weakness is severely limiting mobility or if there is dysphagia or cardiac or respiratory involvement), with consideration of plasmapheresis or IVIG treatment. If there is no improvement in 4-6 weeks, transition to immunosuppression therapy such as azathioprine, methotrexate, or mycophenolate may be considered. With myocardial

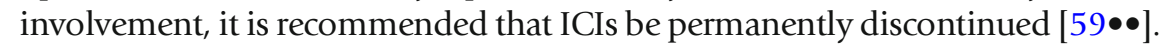
It is unclear if rechallenge of severe ICI-associated myositis with ICI is safe, although one report examining two patients re-challenged 7 or 9 months after myositis resolution did not see a reoccurrence of ICI-associated myositis [60]. In 
a systematic review of ICI-associated neuromuscular complications, 20 of 29 ICI-associated myositis patients improved with immunosuppression [17].

\section{Other medications}

For myositis related to penicillamine, TNF $\alpha$ inhibitors, and interferon beta therapy, cessation of these medications led to improvement in symptoms [19, 21,22 . Caution is recommended with re-challenge of penicillamine and TNF $\alpha$ inhibitors, as re-challenge has been reported to be associated with relapse for both penicillamine-associated myositis $[61,62]$ and TNF $\alpha$ inhibitor-associated myositis [22, 63].

There is limited data for treatment of overlap myositis, but the general principle is to use immunosuppression therapy that also targets the associated rheumatic disease. Systemic sclerosis is the most common rheumatologic disease that overlaps with myositis $[64,65]$. Although there is limited data for immunosuppressive treatment, our center prefers to start with a steroid-sparing agent such as mycophenolate which is commonly used to treat systemic sclerosis, as glucocorticoid treatment is a risk factor for renal crisis [66]. For myositis associated with systemic lupus erythematosus (SLE), patients typically respond well to glucocorticoid treatment; resistant myositis can be treated with additional immunosuppression such as methotrexate [67, 68]. IVIG is usually avoided in patients with systemic lupus erythematosus with antiphospholipid antibodies due to the risk of thromboses. In myositis associated with mixed connective tissue disease, known to respond well to steroids, treatment with increased doses of glucocorticoids usually provides a good response [69]. Rheumatoid arthritis rarely is associated with myositis [70], and myositis is usually initially treated with glucocorticoids with consideration of transition to steroid-sparing agents [71].

\section{Sjogren's syndrome and inclusion body myositis}

Sjogren's syndrome is rarely associated with inclusion body myositis (IBM) [72, 73]. Although IBM is refractory to treatment [74-76], patients with IBM and Sjogren's syndrome have been reported to respond to treatment with immunosuppression $[72,73,77,78]$. Thus, it is our practice to treat Sjogren's syndrome patients with new diagnosis of IBM with immunosuppression, starting with prednisone $1 \mathrm{mg} / \mathrm{kg} /$ day for 2-3 months. If patients respond to glucocorticoids, we initiate steroid-sparing agents such as methotrexate or azathioprine for a trial period while tapering glucocorticoids. Steroid-sparing agents are selected due to side effect profile (Table 1) [79]. However, in our clinical experience, we have seen little response to immunosuppression in these patients.

\section{Myositis associated with malignancy}

When myositis is discovered to be associated with malignancy, a guiding principle is to treat the underlying malignancy, which in some cases has been shown to cure myositis [80-83]. However, this should not preclude the treatment of myositis with immunosuppression. Corticosteroids and IVIG are commonly used to avoid side effects and interactions with chemotherapeutic agents. 
Glucocorticoid treatment should be coordinated around possible surgery, since glucocorticoids can delay wound healing. Prognosis tends to be worse than in idiopathic inflammatory myositis, but depends on the treatment of the underlying malignancy $[33,84]$.

\section{Myositis associated with cGVHD}

In a study examining polymyositis in the setting of cGVHD, 12 patients were treated with either prednisone monotherapy or a combination of prednisone with either azathioprine or cyclosporine, and all showed improvement [42]. Another case series of three patients with dermatomyositis-associated cGVHD showed improvement with immunosuppression via combination treatment of corticosteroids, tacrolimus, rituximab, mycophenolate mofetil, and/or IVIG [43]. Given these results, we recommend steroids with additional immunosuppressive agents if necessary for CGVHD-associated myositis.

\section{Physical/speech therapy and exercise}

\section{Physical therapy and exercise}

We recommend that all patients with myositis be evaluated by a physical therapist that specializes in neuromuscular disease to develop an exercise program. Exercise in myositis has been shown to be safe and effective at improving endurance and strength [85-88]. Patients with polymyositis or dermatomyositis that underwent intensive aerobic exercise combined with resistance training in a randomized controlled trial have improved muscle function, quality of life, and possible reduced disease activity [89]. In fact, a subset of dermatomyositis and polymyositis patients undergoing resistance training showed decreased disease activity [90]. A recent randomized, singleblinded crossover trial examining aerobic training with exercise bicycles showed safety and improved aerobic capacity in patients with inclusion body myositis, providing class II evidence for aerobic training improving cardiopulmonary fitness [91]. We recommend combined aerobic and strength training [86], with avoidance of high-impact and eccentric exercises. Additionally, passive range of motion exercises is useful for extremely weak muscles to prevent contractures. Physical therapists should also work with patients to prevent falls and evaluate patients for assistive devices for ambulation.

We recommend referring patients with dysphagia to speech therapy for a swallow evaluation. Oropharyngeal dysphagia may be addressed with diet modifications and head positioning maneuvers. For refractory dysphagia, patients may require percutaneous endoscopic gastrostomy to maintain nutrition.

\section{Emerging therapies}

\section{Rituximab}

Attention has turned to using rituximab for refractory myositis, for which several studies have shown positive effects for patients with myositis or necrotizing myopathies [57, 92-94]. A randomized, double-blind placebo-controlled trial examining rituximab in myositis did not reach its primary endpoint, 
but most patients had clinical improvement [95•]. These studies support an offlabel use for rituximab in patients with refractory myositis, although additional rigorous studies are needed to evaluate its effectiveness.

\section{Other emerging therapies}

\section{Conclusion}

Several new medications for IIM are currently undergoing clinical trials. If they are found to be effective, further evaluation in treatment of secondary causes of myositis will be warranted. Some of the most promising ones are commented on below.

Abatacept is a fusion protein of $\mathrm{F}_{\mathrm{C}}$ region of IgG1 and CTLA-4 designed to prevent $\mathrm{T}$ cell activation that is currently FDA-approved to treat rheumatoid arthritis. There have been case reports of abatacept successfully used to treat refractory overlap myositis [96] and refractory ICI-associated myositis [97]. A pilot study of 20 patients with refractory dermatomyositis or polymyositis using abatacept found that almost half of their patients showed reduced disease activity and improved muscle performance after treatment for 6 months [98], and there is now a phase III, randomized, double-blind trial to further evaluate abatacept for myositis treatment (ClinicalTrials.gov identifier: NCT02971683).

JAK inhibitors, designed to prevent interferon-induced activation of cytokine receptors, have also been tested in pilot studies for refractory dermatomyositis with promising results, including improved weakness and skin lesions [99101]. The JAK inhibitor tofacitinib is under investigation in the open-label pilot STIR trial (ClinicalTrials.gov identifier: NCT03002649).

Another drug currently under investigation is tocilizumab, a monoclonal antibody directed against interleukin 6 . A case report found normalization of CK in two patients with refractory polymyositis treated with tocilizumab [102], and another showed improvement of both arthritis and weakness in a patient with overlap myositis with rheumatoid arthritis [103]. A randomized controlled phase II trial is underway examining tocilizumab treatment of myositis patients (ClinicalTrials.gov identifier: NCT02043548).

Secondary myositis has several underlying triggers. Here, we have highlighted myositis in the setting of infections, medications, systemic rheumatologic disease, and malignancies. A careful history and workup will detect these underlying causes, for which treatment can be modified accordingly. Severe and persistent cases of secondary myositis require an integrated approach of treating the underlying systemic cause, immunosuppression, and physical therapy.

\section{Acknowledgments}

The authors would like to thank Dr. Andrew Mammen for his careful review of the manuscript, and Dr. Lisa Christopher-Stine, Dr. Christopher Mecoli, Dr. Eleni Tiniakou, Dr. Brittany Adler, Dr. Jemima Albayda, and Dr. Julie Paik for feedback on Table 1. 


\section{Compliance with Ethical Standards}

\section{Conflict of Interest}

Sarah H. Berth declares that she has no conflict of interest. Thomas E. Lloyd declares that he has no conflict of interest.

\section{References and Recommended Reading}

Papers of particular interest, published recently, have been

highlighted as:

- Of importance

•• Of major importance

1. Greenberg SA. Inclusion body myositis: clinical features and pathogenesis. Nat Rev Rheumatol. 2019;15(5):257-72.

2.• Allenbach Y, Mammen AL, Benveniste O, et al. 224th ENMC International Workshop: Clinico-sero-pathological classification of immune-mediated necrotizing myopathies Zandvoort, The Netherlands, 14-16 October 2016. Neuromuscul Disord. 2018;28(1):87-99.

This paper has recent expert consensus guidelines for treatment of anti-HMGCR antibody myopathy.

3. Mammen AL, Allenbach Y, Stenzel W, Benveniste O, Allenbach DY, Benveniste DO, et al. 239th ENMC International Workshop: classification of dermatomyositis, Amsterdam, the Netherlands, 14-16 December 2018. Neuromuscul Disord. 2020;30(1):70-92.

4. Noguchi E, Uruha A, Suzuki S, Hamanaka K, Ohnuki Y, Tsugawa J, et al. Skeletal muscle involvement in antisynthetase syndrome. JAMA Neurol. 2017;74(8):992-9.

5. Lloyd TE, Mammen AL, Amato AA, Weiss MD, Needham M, Greenberg SA. Evaluation and construction of diagnostic criteria for inclusion body myositis. Neurology. 2014;83(5):426-33.

6. Selva-O'Callaghan A, Pinal-Fernandez I, TralleroAraguas E, et al. Classification and management of adult inflammatory myopathies. Lancet Neurol. 2018;17(9):816-28.

Recent comprehensive review of idiopathic inflammatory myopathies.

7.• Moghadam-Kia S, Oddis CV, Aggarwal R. Modern Therapies for Idiopathic Inflammatory Myopathies (IIMs): Role of Biologics. Clin Rev Allergy Immunol. 2017;52(1):81-7.

Overview of biologics therapy for myositis.

8. Aggarwal R, Oddis, C. Management considerations: pharmacologic intervention. Managing Myositis: Springer International Publishing; 2020.

9. Crum-Cianflone NF. Bacterial, fungal, parasitic, and viral myositis. Clin Microbiol Rev. 2008;21(3):473-94

10. Crum NF. Bacterial pyomyositis in the United States. Am J Med. 2004;117(6):420-8.
11. Christin L, Sarosi GA. Pyomyositis in North America: case reports and review. Clin Infect Dis. 1992;15(4):668-77.

12. Crum-Cianflone NF. Nonbacterial myositis. Curr Infect Dis Rep. 2010;12(5):374-82.

13. Mao L, Jin H, Wang M, et al. Neurologic manifestations of hospitalized patients with coronavirus disease 2019 in Wuhan, China. JAMA Neurol. 2020.

This study suggests that muscle manifestations are common in COVID-19.

14. Lloyd TE, Pinal-Fernandez I, Michelle EH, et al. Overlapping features of polymyositis and inclusion body myositis in HIV-infected patients. Neurology. 2017;88(15):1454-60.

This study describes the clinical and pathological manifestations of myositis in HIV-positive patients.

15. Taylor BA, Thompson PD. Statin-associated muscle disease: advances in diagnosis and management. Neurotherapeutics. 2018;15(4):1006-17.

16. Christopher-Stine L, Casciola-Rosen LA, Hong G, Chung T, Corse AM, Mammen AL. A novel autoantibody recognizing $200-\mathrm{kd}$ and $100-\mathrm{kd}$ proteins is associated with an immune-mediated necrotizing myopathy. Arthritis Rheum. 2010;62(9):2757-66.

17. Johansen A, Christensen SJ, Scheie D, Højgaard JLS, Kondziella D. Neuromuscular adverse events associated with anti-PD-1 monoclonal antibodies: systematic review. Neurology. 2019;92(14):663-74.

18. Touat M, Maisonobe T, Knauss S, Ben Hadj Salem O, Hervier B, Auré K, et al. Immune checkpoint inhibitorrelated myositis and myocarditis in patients with cancer. Neurology. 2018;91(10):e985-94.

19. Carroll GJ, Will RK, Peter JB, Garlepp MJ, Dawkins RL. Penicillamine induced polymyositis and dermatomyositis. J Rheumatol. 1987;14(5):995-1001.

20. Seidler AM, Gottlieb AB. Dermatomyositis induced by drug therapy: a review of case reports. J Am Acad Dermatol. 2008;59(5):872-80.

21. Somani AK, Swick AR, Cooper KD, McCormick T. Severe dermatomyositis triggered by interferon beta-1a therapy and associated with enhanced type I interferon signaling. Arch Dermatol. 2008;144(10):1341-9. 
22. Liu SW, Velez NF, Lam C, Femia A, Granter SR, Townsend HB, et al. Dermatomyositis induced by anti-tumor necrosis factor in a patient with juvenile idiopathic arthritis. JAMA Dermatol. 2013;149(10):1204-8.

23. Shukla S, Gultekin SH, Saporta M, et al. Neurology. 2019;92(7):e742-5.

This study describes clinical and pathological features of hydroxychloroquine-induced vacuolar myopathy.

24. Bhansing KJ, van Riel PL, van Engelen BG, et al. Patients with systemic sclerosis/polymyositis overlap have a worse survival rate than patients without it. J Rheumatol. 2016;43(10):1838-43.

25. Moinzadeh P, Aberer E, Ahmadi-Simab K, Blank N, Distler JHW, Fierlbeck G, et al. Disease progression in systemic sclerosis-overlap syndrome is significantly different from limited and diffuse cutaneous systemic sclerosis. Ann Rheum Dis. 2015;74(4):730-7.

26. Allenbach Y, Keraen J, Bouvier AM, Jooste V, Champtiaux N, Hervier B, et al. High risk of cancer in autoimmune necrotizing myopathies: usefulness of myositis specific antibody. Brain. 2016;139(Pt 8):2131-5.

27. Tiniakou E, Mammen AL. Idiopathic inflammatory myopathies and malignancy: a comprehensive review. Clin Rev Allergy Immunol. 2017;52(1):20-33.

28. Chow WH, Gridley G, Mellemkjaer L, et al. Cancer risk following polymyositis and dermatomyositis: a nationwide cohort study in Denmark. Cancer Causes Control. 1995;6(1):9-13.

29. Andras C, Ponyi A, Constantin T, et al. Dermatomyositis and polymyositis associated with malignancy: a 21-year retrospective study. J Rheumatol. 2008;35(3):438-44.

30. Limaye V, Luke C, Tucker G, Hill C, Lester S, Blumbergs $\mathrm{P}$, et al. The incidence and associations of malignancy in a large cohort of patients with biopsy-determined idiopathic inflammatory myositis. Rheumatol Int. 2013;33(4):965-71.

31. Hill CL, Zhang Y, Sigurgeirsson B, Pukkala E, Mellemkjaer L, Airio A, et al. Frequency of specific cancer types in dermatomyositis and polymyositis: a population-based study. Lancet.

2001;357(9250):96-100.

32. Yang Z, Lin F, Qin B, Liang Y, Zhong R. Polymyositis/ dermatomyositis and malignancy risk: a metaanalysis study. J Rheumatol. 2015;42(2):282-91.

33. Andras C, Bodoki L, Nagy-Vincze M, et al. Retrospective analysis of cancer-associated myositis patients over the past 3 decades in a Hungarian Myositis Cohort. Pathol Oncol Res 201923.

34. Qiang JK, Kim WB, Baibergenova A, et al. Risk of Malignancy in Dermatomyositis and Polymyositis. J Cutan Med Surg. 2017;21(2):131-6.

35. Bowerman K, Pearson DR, Okawa J, et al. Malignancy in Dermatomyositis: a retrospective study of 201 patients seen at the University of Pennsylvania. J Am Acad Dermatol 20202.
36. Airio A, Pukkala E, Isomaki H. Elevated cancer incidence in patients with dermatomyositis: a population based study. J Rheumatol. 1995;22(7):1300-3.

37. Wang J, Guo G, Chen G, Wu B, Lu L, Bao L. Metaanalysis of the association of dermatomyositis and polymyositis with cancer. Br J Dermatol. 2013;169(4):838-47.

38. Lu X, Yang H, Shu X, Chen F, Zhang Y, Zhang S, et al. Factors predicting malignancy in patients with polymyositis and dermatomyostis: a systematic review and meta-analysis. PLoS One. 2014;9(4):e94128.

39. Prohic A, Kasumagic-Halilovic E, Simic D, Selmanagic A. Clinical and biological factors predictive of malignancy in dermatomyositis. J Eur Acad Dermatol Venereol. 2009;23(5):591-2.

40. Fiorentino DF, Chung LS, Christopher-Stine L, Zaba L, Li S, Mammen AL, et al. Most patients with cancerassociated dermatomyositis have antibodies to nuclear matrix protein NXP-2 or transcription intermediary factor 1 gamma. Arthritis Rheum. 2013;65(11):2954-62.

41. Jagasia MH, Greinix HT, Arora M, Williams KM, Wolff D, Cowen EW, et al. National Institutes of Health consensus development project on criteria for clinical trials in chronic graft-versus-host disease: I. the 2014 diagnosis and staging working group report. Biol Blood Marrow Transplant. 2015;21(3):389-401e1.

42. Stevens AM, Sullivan KM, Nelson JL. Polymyositis as a manifestation of chronic graft-versus-host disease. Rheumatology (Oxford). 2003;42(1):34-9.

43. Allen JA, Greenberg SA, Amato AA. Dermatomyositislike muscle pathology in patients with chronic graftversus-host disease. Muscle Nerve. 2009;40(4):643-7.

44. Prednisone: drug information uptodate. Waltham, MA (Accessed May 14,2020).

45. Perry LM, Winthrop KL, Curtis JR. Vaccinations for rheumatoid arthritis. Curr Rheumatol Rep. 2014;16(8):431.

46. Methylprednisolone: drug information. UpToDate. Waltham, MA (Accessed May 14, 2020).

47. Azathioprine: drug information. UpToDate. Waltham, MA (Accessed May 14,2020).

48. Methotrexate: drug information. UpToDate. Waltham, MA (Accessed May 14, 2020).

49. Mycophenolate motefil (Cellcept) and mycophenolate sodium (Myfortic): Drug information. UpToDate. Waltham, MA (Accessed May 14, 2020).

50. Immune globulin (intravenous, subcutaneous, and intramuscular): drug information. UpToDate. Waltham, MA (Accessed May 14, 2020).

51. Fridey JL, Kaplan A.A. therapeutic apheresis (plasma exchange or cytapheresis): indications and technology. UpToDate. February 12, 2020 ed. Waltham, MA (Accessed May 14, 2020).

52. Kaplan AA, Fridey, J.L. Therapeutic apheresis (plasma exchange or cytapharesis): complications. UpToDate. May 8, 2020 ed. Waltham, MA (Accessed May 14, 2020). 
53. Rituximab: Drug Information. UpToDate. Waltham, MA (Accessed May 14, 2020).

54. Mohassel P, Mammen AL. Anti-HMGCR myopathy. J Neuromuscul dis. 2018;5(1):11-20.

This is a comprehensive review of anti-HMGCR myopathy.

55. Tiniakou E, Rivera E, Mammen AL, Christopher-Stine L. Use of proprotein convertase subtilisin/kexin type 9 inhibitors in statin-associated immune-mediated necrotizing myopathy: a case series. Arthritis Rheum. 2019;71(10):1723-6.

56. Mammen AL, Tiniakou E. Intravenous immune globulin for statin-triggered autoimmune myopathy. N Engl J Med. 2015;373(17):1680-2.

57. Landon-Cardinal O, Allenbach Y, Soulages A, Rigolet A, Hervier B, Champtiaux N, et al. Rituximab in the treatment of refractory anti-HMGCR immune-mediated necrotizing myopathy. J Rheumatol. 2019;46(6):623-7.

58. Ashton C, Junckerstorff R, Bundell C, Hollingsworth P, Needham $M$. Treatment and outcomes in necrotising autoimmune myopathy: an Australian perspective. Neuromuscul Disord. 2016;26(11):734-40.

59.• Brahmer JR, Lacchetti C, Schneider BJ, et al. Management of immune-related adverse events in patients treated with immune checkpoint inhibitor therapy: American Society of Clinical Oncology Clinical Practice Guideline. J Clin Oncol. 2018;36(17):1714-68.

This paper provides expert guidelines on treatment of ICImyositis.

60. Delyon J, Brunet-Possenti F, Leonard-Louis S, Arangalage D, Baudet M, Baroudjian B, et al. Immune checkpoint inhibitor rechallenge in patients with immune-related myositis. Ann Rheum Dis. 2019;78(11):e129.

61. Takahashi K, Ogita T, Okudaira H, Yoshinoya S, Yoshizawa H, Miyamoto T. D-penicillamine-induced polymyositis in patients with rheumatoid arthritis. Arthritis Rheum. 1986;29(4):560-4.

62. Petersen J, Halberg P, Hojgaard K, et al. Penicillamineinduced polymyositis-dermatomyositis. Scand J Rheumatol. 1978;7(2):113-7.

63. Riolo G, Towheed TE. Anti-tumor necrosis factor inhibitor therapy-induced dermatomyositis and fasciitis. J Rheumatol. 2012;39(1):192-4.

64. Maundrell A, Proudman S, Limaye V. Prevalence of other connective tissue diseases in idiopathic inflammatory myopathies. Rheumatol Int. 2019;39(10):1777-81.

65. Iaccarino L, Gatto $M$, Bettio S, Caso F, Rampudda M, Zen $\mathrm{M}$, et al. Overlap connective tissue disease syndromes. Autoimmun Rev. 2013;12(3):363-73.

66. Paik J, Varga J. Neuromuscular manifestations of systemic sclerosis (scleroderma). Feb 05. 2019 ed. Walthan, MA: UpToDate; 2019.

67. Liang Y, Leng RX, Pan HF, Ye DQ. Associated variables of myositis in systemic lupus erythematosus: a crosssectional study. Med Sci Monit. 2017;23:2543-9.

68. Maazoun F, Frikha F, Snoussi M, Kaddour N, Masmoudi H, Bahloul Z. Systemic lupus erythematosus myositis overlap syndrome: report of 6 cases. Clin Pract. 2011;1(4):e89.

69. Bonin CC, da Silva BS, Mota LM, et al. Severe and refractory myositis in mixed connective tissue disease: a description of a rare case. Lupus. 2010;19(14):1659-61.

70. Nakajima A, Yoshino K, Soejima M, Kawaguchi Y, Satoh T, Kuwana M, et al. High frequencies and coexisting of myositis-specific autoantibodies in patients with idiopathic inflammatory myopathies overlapped to rheumatoid arthritis. Rheumatol Int.

2012;32(7):2057-61.

71. Overview of the systemic and nonarticular manifestations of rheumatoid arthritis [Internet]. [cited May 13, 2020].

72. Colafrancesco S, Priori R, Gattamelata A, Picarelli G, Minniti A, Brancatisano F, et al. Myositis in primary Sjogren's syndrome: data from a multicentre cohort. Clin Exp Rheumatol. 2015;33(4):457-64.

73. Kanellopoulos P, Baltoyiannis C, Tzioufas AG. Primary Sjogren's syndrome associated with inclusion body myositis. Rheumatology (Oxford). 2002;41(4):440-4.

74. Benveniste O, Guiguet M, Freebody J, Dubourg O, Squier W, Maisonobe T, et al. Long-term observational study of sporadic inclusion body myositis. Brain. 2011;134(Pt 11):3176-84.

75. Dalakas MC, Sonies B, Dambrosia J, Sekul E, Cupler E, Sivakumar K. Treatment of inclusion-body myositis with IVIg: a double-blind, placebo-controlled study. Neurology. 1997;48(3):712-6.

76. Cherin P, Pelletier S, Teixeira A, Laforet P, Simon A, Herson $S$, et al. Intravenous immunoglobulin for dysphagia of inclusion body myositis. Neurology. 2002;58(2):326.

77. Misterska-Skora M, Sebastian A, Dziegiel P, et al. Inclusion body myositis associated with Sjogren's syndrome. Rheumatol Int. 2013;33(12):3083-6.

78. Migkos MP, Sarmas I, Somarakis GA, Voulgari P, Tsamis K, Drosos A. Sjogren syndrome associated with inflammatory muscle diseases. Mediterr J Rheumatol. 2018;29(2):92-6.

79. Lloyd TE. Management of inclusion body myositis. January 3, 2020 ed. Waltham, MA: UpToDate.

80. Masuda H, Urushibara M, Kihara K. Successful treatment of dermatomyositis associated with adenocarcinoma of the prostate after radical prostatectomy. J Urol. 2003;169(3):1084.

81. Yoshinaga A, Hayashi T, Ishii N, et al. Successful cure of dermatomyositis after treatment of nonseminomatous testicular cancer. Int J Urol. 2005;12(6):593-5.

82. Bonnetblanc JM, Bernard P, Fayol J. Dermatomyositis and malignancy. A multicenter cooperative study. Dermatologica. 1990;180(4):212-6.

83. Tallai B, Flasko T, Gyorgy T, et al. Prostate cancer underlying acute, definitive dermatomyositis: successful treatment with radical perineal prostatectomy. Clin Rheumatol. 2006;25(1):119-20. 
84. Ponyi A, Constantin T, Garami M, et al. Cancerassociated myositis: clinical features and prognostic signs. Ann N Y Acad Sci. 2005;1051:64-71.

85. Arnardottir S, Alexanderson H, Lundberg IE, Borg K. Sporadic inclusion body myositis: pilot study on the effects of a home exercise program on muscle function, histopathology and inflammatory reaction. J Rehabil Med. 2003;35(1):31-5.

86. Johnson LG, Collier KE, Edwards DJ, Philippe DL, Eastwood PR, Walters SE, et al. Improvement in aerobic capacity after an exercise program in sporadic inclusion body myositis. J Clin Neuromuscul Dis. 2009;10(4):178-84.

87. Alexanderson $\mathrm{H}$. Exercise in inflammatory myopathies, including inclusion body myositis. Curr Rheumatol Rep. 2012;14(3):244-51.

88. Spector SA, Lemmer JT, Koffman BM, Fleisher TA, Feuerstein IM, Hurley BF, et al. Safety and efficacy of strength training in patients with sporadic inclusion body myositis. Muscle Nerve. 1997;20(10):1242-8.

89. Alemo Munters L, Dastmalchi M, Andgren V, Emilson C, Bergegård J, Regardt M, et al. Improvement in health and possible reduction in disease activity using endurance exercise in patients with established polymyositis and dermatomyositis: a multicenter randomized controlled trial with a 1-year open extension followup. Arthritis Care Res. 2013;65(12):1959-68.

90. Alexanderson H, Dastmalchi M, Esbjornsson-Liljedahl $\mathrm{M}$, et al. Benefits of intensive resistance training in patients with chronic polymyositis or dermatomyositis. Arthritis Rheum. 2007;57(5):768-77.

91. Wallace A, Pietrusz A, Dewar E, Dudziec M, Jones K, Hennis $P$, et al. Community exercise is feasible for neuromuscular diseases and can improve aerobic capacity. Neurology. 2019;92(15):e1773-85.

92. Fasano S, Gordon P, Hajji R, Loyo E, Isenberg DA. Rituximab in the treatment of inflammatory myopathies: a review. Rheumatology (Oxford). 2017;56(1):26-36.

93. Valiyil R, Casciola-Rosen L, Hong G, Mammen A, Christopher-Stine L. Rituximab therapy for myopathy associated with anti-signal recognition particle antibodies: a case series. Arthritis Care Res. 2010;62(9):1328-34.

94. Pinal-Fernandez I, Parks C, Werner JL, Albayda J, Paik JJ, Danoff SK, et al. Longitudinal course of disease in a large cohort of myositis patients with autoantibodies recognizing the signal recognition particle. Arthritis Care Res. 2017;69(2):263-70.
95. Oddis CV, Reed AM, Aggarwal R, et al. Rituximab in the treatment of refractory adult and juvenile dermatomyositis and adult polymyositis: a randomized, placebophase trial. Arthritis Rheum. 2013;65(2):314-24.

Although this study did not meet its primary endpoint, 83\% patients with refractory dermatomyositis or polymyositis met definition of improvement.

96. Kerola AM, Kauppi MJ. Abatacept as a successful therapy for myositis-a case-based review. Clin Rheumatol. 2015;34(3):609-12.

97. Salem JE, Allenbach Y, Vozy A, Brechot N, Johnson DB, Moslehi JJ, et al. Abatacept for severe immune checkpoint inhibitor-associated myocarditis. N Engl J Med. 2019;380(24):2377-9.

98. Tjarnlund A, Tang Q, Wick C, et al. Abatacept in the treatment of adult dermatomyositis and polymyositis: a randomised, phase IIb treatment delayed-start trial. Ann Rheum Dis. 2018;77(1):55-62.

99. Ladislau L, Suarez-Calvet X, Toquet S, et al. JAK inhibitor improves type I interferon induced damage: proof of concept in dermatomyositis. Brain. 2018;141(6):1609-21.

100. Kurtzman DJ, Wright NA, Lin J, et al. Tofacitinib citrate for refractory cutaneous dermatomyositis: an alternative treatment. JAMA Dermatol. 2016;152(8):944-5.

101. Paik JJ, Christopher-Stine L. A case of refractory dermatomyositis responsive to tofacitinib. Semin Arthritis Rheum. 2017;46(4):e19.

102. Narazaki M, Hagihara K, Shima Y, Ogata A, Kishimoto T, Tanaka T. Therapeutic effect of tocilizumab on two patients with polymyositis. Rheumatology (Oxford). 2011;50(7):1344-6.

103. Kondo M, Murakawa Y, Matsumura T, Matsumoto O, Taira M, Moriyama M, et al. A case of overlap syndrome successfully treated with tocilizumab: a hopeful treatment strategy for refractory dermatomyositis? Rheumatology (Oxford). 2014;53(10):1907-8.

\section{Publisher's Note}

Springer Nature remains neutral with regard to jurisdictional claims in published maps and institutional affiliations. 